\title{
Cardiocirculatory intraoperative assessment during single-shot caudal anaesthesia in children: comparison between levobupivacaine and ropivacaine
}

\author{
Comportamento cardiocircolatorio intraperatorio durante anestesia caudale single-shot in età pediatrica: \\ confronto fra levobupivacaina e ropivacaina
}

A. Gentili, ${ }^{1}$ L. Pasini, ${ }^{1}$ V. Bachiocco, ${ }^{1}$ V. Landuzzi, ${ }^{1}$ L. Giuntoli, ${ }^{1}$ M. Lima,,${ }^{2}$ S. Baroncini ${ }^{1}$

Key words: caudal anaesthesia, children, levobupivacaine, ropivacaine, cardiocirculatory trend

\section{Abstract}

Background: Caudal block with levobupivacaine or ropivacaine is the most commonly used regional anaesthesia in children.

Methods: The aim of study was to compare the cardiocirculatory profile induced in two matched groups of young patients, submitted to caudal anaesthesia with levobupivacaine or ropivacaine for an elective subumbilical surgery. Sixty children were enrolled: thirty received levopubivacaine $0.25 \%$ and thirty ropivacaine $0.2 \%$. Intraoperative heart rate (HR), systolic blood pressure (SBP), diastolic blood pressure (DBP) were monitored at following times: Ta0 (after anaesthesia induction), Ta1 (after caudal anaesthesia), Ta2 (five minutes later), Ta3 (ten minutes later), Ts1 (at surgical incision), Ts2, Ts3, Ts4, Ts5 (every 10 minutes during surgery), Taw (at the awakening).

Results: In both groups the cardiocirculatory trend

Department of Paediatric Anaesthesia and Intensive Care

S.Orsola-Malpighi Hospital - Bologna University, Italy

Department of Paediatric Surgery,

S.Orsola-Malpighi Hospital - Bologna University, Italy

Indirizzo per la corrispondenza (Corresponding author):

Andrea Gentili

Via Muratori, 3

40054 Budrio - Bologna - Italy

Email: andrea_gentili@libero.it

Tel: 0039516363650 - Fax: 0039516364690 remained within normal ranges at all times considered, demonstrating the safety of the method with both drugs. Both groups showed a similar trend at the different monitoring times: low decrease in HR, SBP and DBP after caudal block, slight increase in parameters after skin incision, slight decrease during surgery, increase at awakening. Regarding SBP and DBP, the levobupivacaine group children generally showed higher levels compared to the ropivacaine group, especially for DBP.

Conclusions: Paediatric caudal anaesthesia is an effective method with an very infrequent complication rate. Possible hypotheses for differing haemodynamic behaviour could include a stronger vasoconstriction reflex of innervated areas during caudal anaesthesia with levobupivacaine and a lower levobupivacaine induced block of the sympathetic fibers, related to different pharmacokinetic profile of low concentrations of the local anaesthetics used in paediatric epidural space.

\section{Riassunto}

Introduzione: L'anestesia caudale con levobupivacaina o ropivacaina è la più comunemente usata in età pediatrica. Metodi: Scopo dello studio è paragonare il profilo cardiocircolatorio in due gruppi di pazienti sottoposti ad anestesia caudale con levobupivacaina o ropivacaina durante interventi a livello sottombelicale di elezione. Sessanta bambini sono stati studiati: trenta hanno utilizzato levobupivacaina $(0.25 \%)$, gli altri trenta ropivacaina $(0.2 \%)$. Durante l'intervento sono stati monitorizzati frequenza cardiaca (FC), pressione arteriosa sistolica (PAS) e 
diastolica (PAD) nei seguenti tempi: Ta0 (al termine dell'induzione), Ta1 (dopo anestesia caudale), Ta2, Ta3 (5, 10 minuti dopo la caudale), Ts1 (al momento dell'incisione), Ts2, Ts3, Ts4, Ts5 (ogni 10 minuti durante l'intervento chirurgico), Taw (al risveglio).

Risultati: In entrambi i gruppi l'andamento cardiocircolatorio è stato normale, dimostrando una tecnica sicura con entrambi i farmaci. Il comportamento emodinamico è stato simile per i due farmaci nei diversi tempi studiati: lieve riduzione di FC, PAS e PAD dopo la caudale, modesto aumento dei parametri all'incisione della cute con successiva riduzione durante l'intervento e incremento al risveglio. I bambini trattati con levobupivacaina hanno evidenziato valori di PAS e PAD più elevati rispetto a quelli trattati con ropivacaina. Tale comportamento è più evidente per la PAD.

Conclusioni: In età pediatrica l'anestesia caudale rappresenta una metodica efficace e priva di complicanze. Il diverso comportamento emodinamico fra i due farmaci potrebbe essere spiegato da un maggiore riflesso vasocostrittore delle fibre simpatiche non bloccate dalla caudale per i pazienti trattati con levobupivacaina o un differente profilo farmacocinetico dei due anestetici nello spazio peridurale.

\section{Introduction}

The advantages of regional anaesthesia are well known: reduction of metabolic and hormonal effects of the surgical stress response, reduction of the general anaesthetics required, good efficacy for postoperative analgesia. Caudal block is the most commonly used regional anaesthesia in children. It is in fact the technique of choice for operations on T9-T10 methamers. The majority of day surgery procedures below the diaphragm can thus be carried out with this single shot technique. Furthermore, caudal anaesthesia is easy to perform. ${ }^{1,2}$

In clinical practice, one of the main topics has become the choice of an effective and safe drug, or combination of drugs. ${ }^{3,4}$ Bupivacaine has for many years been the most commonly given local anaesthetic of prolonged effect for paediatric caudal blocks. However several reports have described serious and difficult to treat cardiovascular and central-nervous toxicity when this agent was given at toxic doses or inadvertently injected into the intravascular space. Bupivacaine, on account of its avidity to the sodium channels, can in fact precipitate severe cardiovascular collapse, as a result of reduced heart contractility or impaired diastolic function, and negative effects upon conduction or ventricular arrhythmias. ${ }^{5,6,7,8}$

More recently, two other local anaesthetics have been introduced: ropivacaine and levobupivacaine. Ropiva- caine, the first single levorotatory isomer formulation for clinical use, is a long-acting drug, very similar in structure to bupivacaine, but apparently with a lower cardiac and neuro toxicity and a slightly greater sensory selectivity. ${ }^{9,10,11}$ Compared to its congener, levobupivacaine, the single levorotatory isomer of bupivacaine, presents a slightly lower myocardial depression, arrhythmogenic effect and neuro toxicity, while retaining similar local anaesthetic properties. ${ }^{12,13}$ On the whole, therefore, preliminary evidence suggests that ropivacaine and levobupivacaine may be associated with less systemic toxicity. ${ }^{14,15}$ Clinical studies focused on intra and postoperative analgesia confirm their safety and show their increasing use for paediatric caudal anaesthesia. ${ }^{16,17}$ To our knowledge, few studies on the intraoperative cardiovascular performance during caudal anaesthesia in children have been conducted and no investigation on the intraoperative haemodynamic comparison between levobupivacaine and ropivacaine. ${ }^{18}$

The aim of the present study was to compare the cardiocirculatory profile induced in two matched groups of young patients, submitted to caudal anaesthesia with levobupivacaine or ropivacaine for an elective sub-umbilical surgical procedure.

\section{Material and Methods}

Heart rate and blood arterial pressures (systolic and diastolic) were taken as parameters of reference in the study. To detect a significant difference, a study group size of 60 children was needed to achieve a power of $90 \%[\alpha=5 \%]$. Randomization was performed with a computer-driven random number sequence and sealed in an opaque envelope. The study was approved by the Hospital's Ethical Committee and received written informed consent.

All children scheduled for a surgery due to phimosis or a pathology of the peritoneal-vaginal ductus were eligible for the study. The exclusion criteria included: emergency surgery, a known hypersensitivity to amide-type local anaesthetic, age lower than 2 years and greater than seven, a high anaesthesia risk class (ASA III - IV), severe renal, hepatic, respiratory or cardiac disease, neurological or neuromuscular disease, haemostasis and coagulation disorders, systemic sepsis, infection of the soft tissues over/around the sacral iatus. After obtaining written consent from parents, the sealed opaque envelope that assigned a child to the designated group was opened and the child recruited.

Sixty children were enrolled between September 2008 and January 2010. Thirty children received levopubivacaine and thirty ropivacaine. Table 1 shows the children's characteristics according to the randomization group. Table 2 illustrates surgical procedures according to the same criteria. 


\begin{tabular}{|c|c|c|c|}
\hline \multicolumn{4}{|c|}{ PATIENTS AND CLINICAL DATA } \\
\hline Group & Levobupivacaine $0.25 \%\left(n^{\circ} 30\right)$ & Ropivacaine $0.20 \%\left(n^{\circ} 30\right)$ & $p$ \\
\hline Age (years) & $4.4 \pm 1.5$ & $4.5 \pm 1.1$ & $\mathrm{~ns}$ \\
\hline Weight (kg) & $16.9 \pm 5.1$ & $16.5 \pm 3.1$ & $\mathrm{~ns}$ \\
\hline Gender (M/F) & $27 / 3$ & $26 / 4$ & $\mathrm{~ns}$ \\
\hline ASA risk class (I/II) & $15 / 15$ & $18 / 12$ & $\mathrm{~ns}$ \\
\hline Duration of surgery (min) & $41 \pm 13$ & $44 \pm 11$ & $\mathrm{~ns}$ \\
\hline
\end{tabular}

Table 2

SURGICAL INTERVENTIONS DIVIDED ACCORDING TO LOCAL ANAESTHETIC ADMINISTERED

Surgical interventions

Herniorraphy

Circumcision

Hydrocoele repair

Removal of peritoneal-vaginal ductus cyst
Levobupivacaine $0.25 \%$

5
18
6
1

Ropivacaine $0.20 \%$

5

17

7

1
A standardized pre-anaesthesia consisting of diazepam $(0.2 \mathrm{mg} / \mathrm{kg})$ and atropine $(0.015 \mathrm{mg} / \mathrm{kg})$ orally was administered 45 minutes before anaesthesia induction. In children five years old or less, anaesthesia was induced through a mixture of oxygen, air and sevoflurane at a concentration increasing from $1 \%$ to $8 \%$. For children older than five years, intravenously propofol $(2.5-3 \mathrm{mg} / \mathrm{kg})$ was used. In all children, general anaesthesia was maintained through a mixture of oxygen, air and sevoflurane (endtidal concentration between 1.5 and 2.5\%). The airway was controlled with a laryngeal mask and ventilation was maintained spontaneously or assisted in order to obtain an end-tidal $\mathrm{CO}_{2}\left(\mathrm{PETCO}_{2}\right)<50 \mathrm{mmHg}$.

Caudal anaesthesia was then performed as follows. The child was turned onto the left lateral position and $1 \mathrm{ml} / \mathrm{kg}$ of local anaesthetic was injected into the caudal space using a 22-gauge needle (Epican Paed Caudal ${ }^{\circledR}$, B-Braun, Melsungen, Germany). The local anaesthetic solution was injected in approximately $60 \mathrm{sec}$. In children in the ropivacaine group, the anaesthetic was given at a concentration of $0.2 \%$ and a dosage of $2 \mathrm{mg} / \mathrm{kg}$, in the others levobuvicaine was administered at a concentration of $0.25 \%$ and a dosage of $2.5 \mathrm{mg} / \mathrm{kg}$. A minimum time interval of 10 minutes was established between the completion of caudal anaesthesia and skin incision. Dextrose $5 \%$ in quarter-strength normal saline solution $(0.2 \%$ $\mathrm{NaCl}$ ) and lactated Ringer's solution were administered according to the following scheme: during the first hour, in children under 3 yrs the infusion rate was $20 \mathrm{ml} / \mathrm{kg}$, in older children the rate was $15 \mathrm{ml} / \mathrm{kg}$; the infusion dosage was $8-10 \mathrm{ml} / \mathrm{kg} / \mathrm{h}$ for all patients in the subsequent hours. Intraoperative heart rate (HR), systolic blood pressure (SBP) and diastolic blood pressure (DBP) were monitored (Integrated Modular HP System ${ }^{\bullet}$, Hewlett-Packard, Palo Alto $\mathrm{Ca}$ ) and registered at the following times: $\mathrm{Ta} 0$ (when anaesthesia induction was completed), Ta1 (when caudal anaesthesia was completed), Ta2 (five minutes later) , Ta3 (ten minutes later), Ts1 (at the surgical incision), Ts2, Ts3, Ts4, Ts5 (every 10 minutes during surgery), Taw (at the awakening). Arterial oxygen saturation $\left(\mathrm{SpO}_{2}\right)$ by pulse oximetrix, $\mathrm{PETCO}_{2}$ and body temperature (Integrated Modular HP System ${ }^{\bullet}$, Hewlett-Packard, Palo Alto Ca) were also continuously monitored.

In our study caudal block effectiveness at the start of surgery was defined as the absence of gross or subtle movements and the absence of significant (> 20\%) increase in pulse rate or blood pressure. The values (mean and range) reported by Gregory as normal according to age class were assumed as standard point of reference. ${ }^{19}$ Intraoperative bradycardia and arterial hypotension are defined as a decrease of $>30 \%$ from baseline. ${ }^{20}$

\section{Statistics}

Analysis of data was performed with the Stata 7 software program. Data underwent descriptive statistics. To study the effects of levobupivacaine and ropivacaine on HR, SBP, DBP an analysis between samples (over time) and within samples (time by time) was carried out. For the first purpose, variance analysis and Student's test were applied to compare within the same sample data recorded at a given time with those recorded at the subsequent times. For the second objective, Student's test was applied to compare data collected in a group at each time with those collected in the other sample at the corresponding time.

\section{Results}

The block was efficacious in all patients. No children needed an additional intravenous analgesic intraoperatively. Furthermore, there were no complications either in relation to the general anaesthesia or the surgery. No 


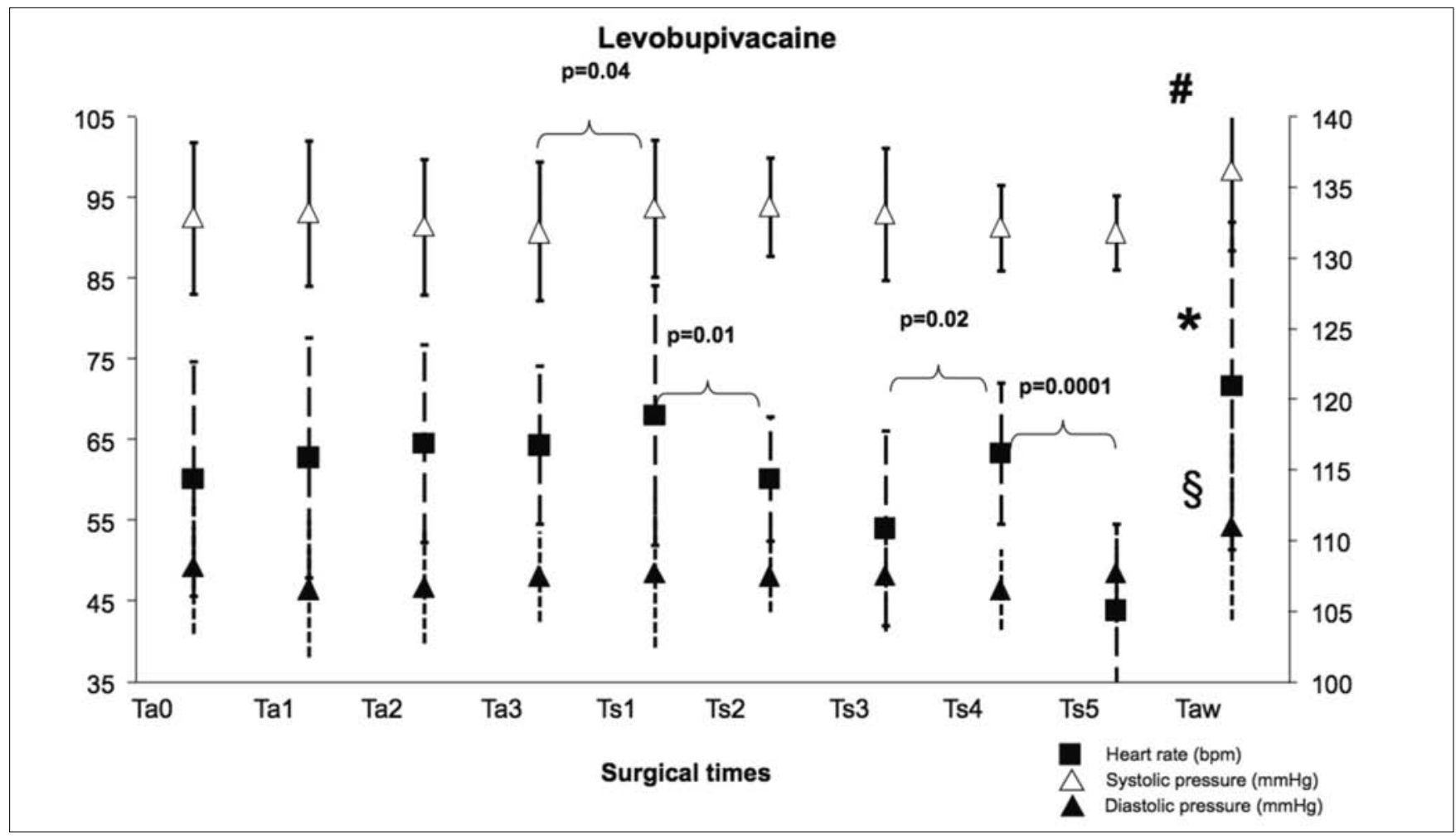

Figure 1.

Trend of HR, SBP, DBP in the levobupivacaine group at the following times: Ta0 (at the end of anaesthesia induction), Ta1 (at the end of caudal anaesthesia), Ta2 (five minutes later), Ta3 (ten minutes later), Ts1 (at the surgical incision), Ts2, Ts3, Ts4, Ts5 (every 10 minutes during surgery), Taw (at the awakening). The figure shows the significance for the three parameters at the different times. At Taw the symbols *, \#, § indicate statistical significance respectively for HR, SBP, DBP compared to all the preceding times.

blood, blood products or plasma expanders were ever administered.

On the whole 1028 measurements were recorded. None of the heart rate and systolic blood pressure values significantly differed from the range values for age class. Only one 5-year-old male child treated with ropivacaine showed an episode of diastolic hypotension $(28 \mathrm{mmHg})$ at time Ta3. A doubled fluids infusion rate promptly restored normal values, without the use of vasoactive drugs.

The global values (mean and SD) for each variable were: HR $114.7 \pm 17.2$ in the levobupivacaine group and $116.4 \pm 13.8$ in the ropivacaine group $(p=n s)$; SBP $92.7 \pm 7.1 \mathrm{mmHg}$ in the levobupivacaine group and $90.1 \pm 8.3 \mathrm{mmHg}$ in the ropivacaine group $(\mathrm{p}=\mathrm{ns})$; DBP $48.7 \pm 6.7 \mathrm{mmHg}$ in the levobupivacaine group and $44.5 \pm 5.6 \mathrm{mmHg}$ in the ropivacaine group $(\mathrm{p}<0.02)$.

Intra-sample differences over time.

Considering the trend of cardiocirculatory parameters in each of the two groups, a substantial agreement in trends at the various times can be noted throughout the entire procedure.

In the levobupivacaine group (Fig 1) SBP shows a low decrease after caudal anaesthesia. All three parameters increase after skin incision, with significance in Ts1 for SBP $(p=0.04)$. During surgery pressure values were constant, the HR being significantly lower at Ts2 with respect Ts1 $(\mathrm{p}=0.01)$, at Ts 4 with respect Ts3 $(\mathrm{p}=0.02)$ and at Ts 4 with respect $T s 5(p=0.0001)$. A significant peak pressure and heart rate increase was registered at the awakening (Taw) compared with all the other times.

A similar trend was also seen in the ropivacaine group (Fig 2). HR, SBP, DBP show a moderate decrease after the caudal block. The heart rate showed a statistically significant tendency to decrease between $\mathrm{Ta} 2$ and Ta3 $(\mathrm{p}=0.05)$. After the skin incision all three parameters increase at Ts 1 and in particular HR and SBP significantly compared to Ta3 (respectively $\mathrm{p}=0.05$ and $\mathrm{p}=0.04$ ). During the course of the surgery the three parameters tended to decrease slightly: in particular significance for HR was noted between Ts 1 and Ts $2(\mathrm{p}=0.03)$, between Ts3 and Ts4 ( $\mathrm{p}=0.02)$ between Ts 4 and Ts5 $(\mathrm{p}=0.01)$, for SBP and DBP between Ts 1 and Ts2 (respectively $\mathrm{p}=0.05$ and $\mathrm{p}=0.04)$. The heart rate and the systolic blood pressure increase significantly compared to all the other respective times at the awakening.

Inter-samples differences time by time.

Regarding heart rate, no significant difference was identified between groups at any time (Fig 3).

With regards systolic blood pressure, Fig 4 illustrates values (mean and SD) at each observation. The levobupivacaine group generally shows higher values compared to the ropivacaine group. A significant difference was seen at 


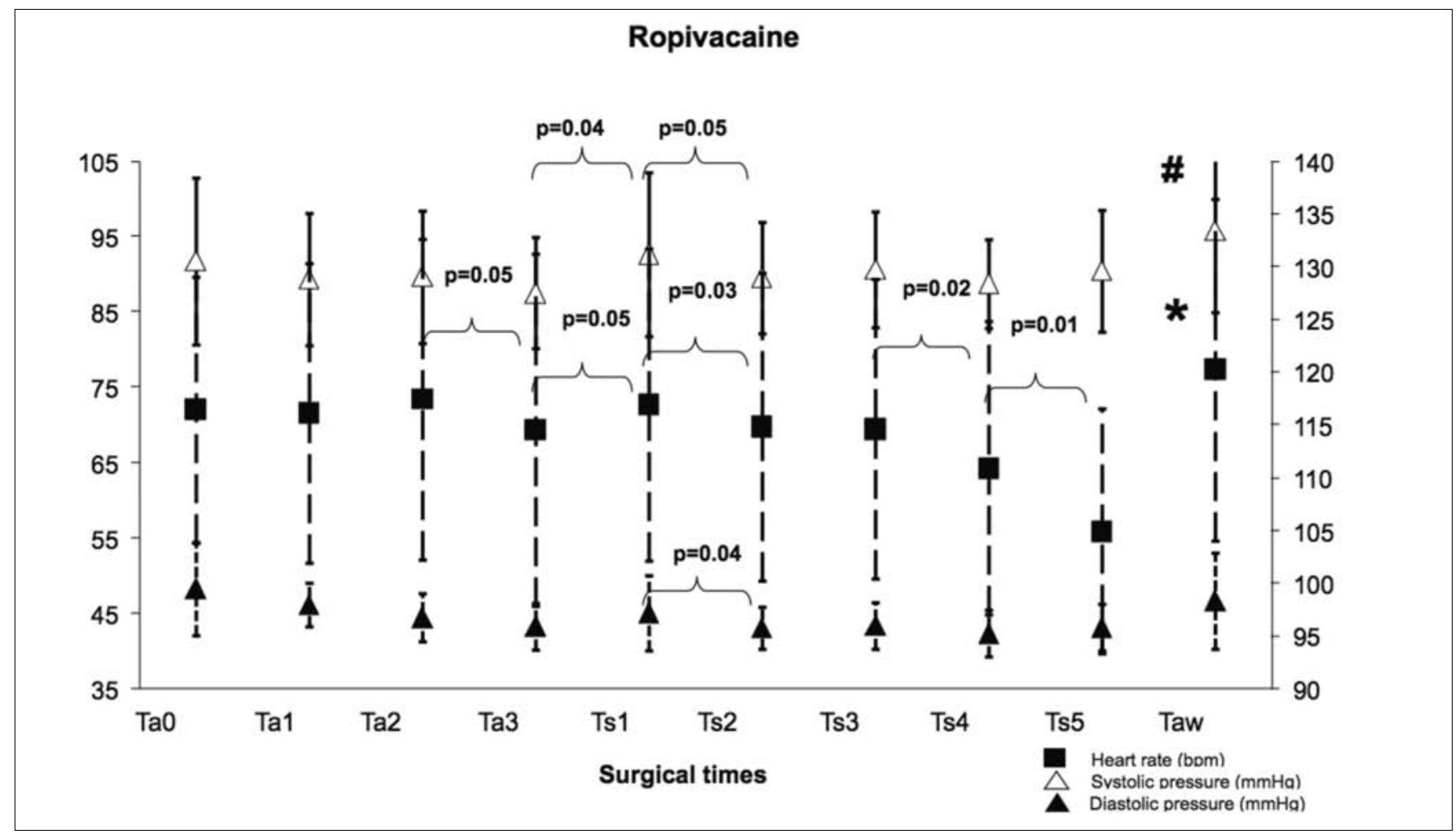

Figure 2.

Trend of HR, SBP, DBP in the ropivacaine group at the following times: Ta0 (at the end of anaesthesia induction), Ta1 (at the end of caudal anaesthesia), Ta2 (five minutes later), Ta3 (ten minutes later), Ts1 (at the of surgical incision), Ts2, Ts3, Ts4, Ts5 (every 10 minutes during surgery), Taw (at the awakening). The figure shows the significance for the three parameters at the different times. At Taw the symbols ${ }^{*}$, \# indicate a statistical significance respectively of HR and SBP compared to all the preceding times.

TS2, where the levobupivacaine group showed significantly higher values $(93.9 \pm 6.1 \mathrm{mmHg}$ vs $89.5 \pm 9.3$ $\mathrm{mmHg}$ with $\mathrm{p}=0.03$ ).

Regarding diastolic blood pressure, higher levels in the levobupivacaine group were noted compared to the children treated with ropivacaine at each time considered (Fig 5). In particular, significance is present at the following five times: Ta3 $(48.1 \pm 5.6 \mathrm{mmHg}$ vs $43.2 \pm 3.1$ $\mathrm{mmHg}$ with $\mathrm{p}=0.01)$, Ts2 $(48.1 \pm 4.4 \mathrm{mmHg}$ vs $43.0 \pm$ $2.8 \mathrm{mmHg}$ with $\mathrm{p}=0.006)$, Ts3 $(48.2 \pm 6.9 \mathrm{mmHg}$ vs $43.3 \pm 3.1 \mathrm{mmHg}$ with $\mathrm{p}=0.002), \mathrm{Ts} 4(46.5 \pm 5.0 \mathrm{mmHg}$ vs $42.3 \pm 3.1 \mathrm{mmHg}$ with $\mathrm{p}=0.02)$, Ts 5 ( $48.5 \pm 6.1$ $\mathrm{mmHg}$ vs $43.1 \pm 3.1 \mathrm{mmHg}$ with $\mathrm{p}=0.02)$ and Taw $(54.3$ \pm 9.6 vs $46,6 \pm 6.4$ with $\mathrm{p}=0.01)$.

\section{Discussion}

Caudal block is the most commonly used regional anaesthesia in children. It combines the advantages of a simple and safe procedure with a good postoperative analgesia. ${ }^{4}$ Since ropivacaine and levobupivacaine became available, regional anaesthetic techniques, in particular caudal anaesthesia, have become increasingly more wide-spread among the paediatric population, rapidly achieving reliability in terms of safety. ${ }^{11,12}$ The lack of serious cardiocir- culatory side effects associated with these two local anaesthetics, represents one of the main factors allowing us to believe that the safety of this technique is consolidated. To our knowledge, though, no findings about the comparison on the intraoperative cardiocirculatory performance between ropivacaine and levobupivacaine have been reported during caudal block in children.

When regional anaesthetic techniques are used, three methodological points need to be discussed: the anaesthetic concentrations, the relative potency and the volume of administration.

In the study here reported, we used the commercially available concentrations i.e. $0.25 \%$ for levobupivacaine and $0.20 \%$ for ropivacaine. Among studies already published, some authors chose the same option (commercial distinction), others used the same concentration (either at $0.25 \%$ or $0.20 \%$ ) while others tested lower concentrations $(0.125 \%){ }^{16,17,21,22,23,24,25,26,27}$ The objective of all these investigations was to examine the clinical effectiveness of such drugs in terms of postoperative analgesia and motor blockade. A recent study on the haemodynamic effects of levobupivacaine after paediatric caudal anaesthesia evaluated by transesophageal Doppler was carried out with levobupivacaine $0.25 \% .^{18}$

To compare two local anaesthetics, the definition of their relative potency is an important step. Its inference from 


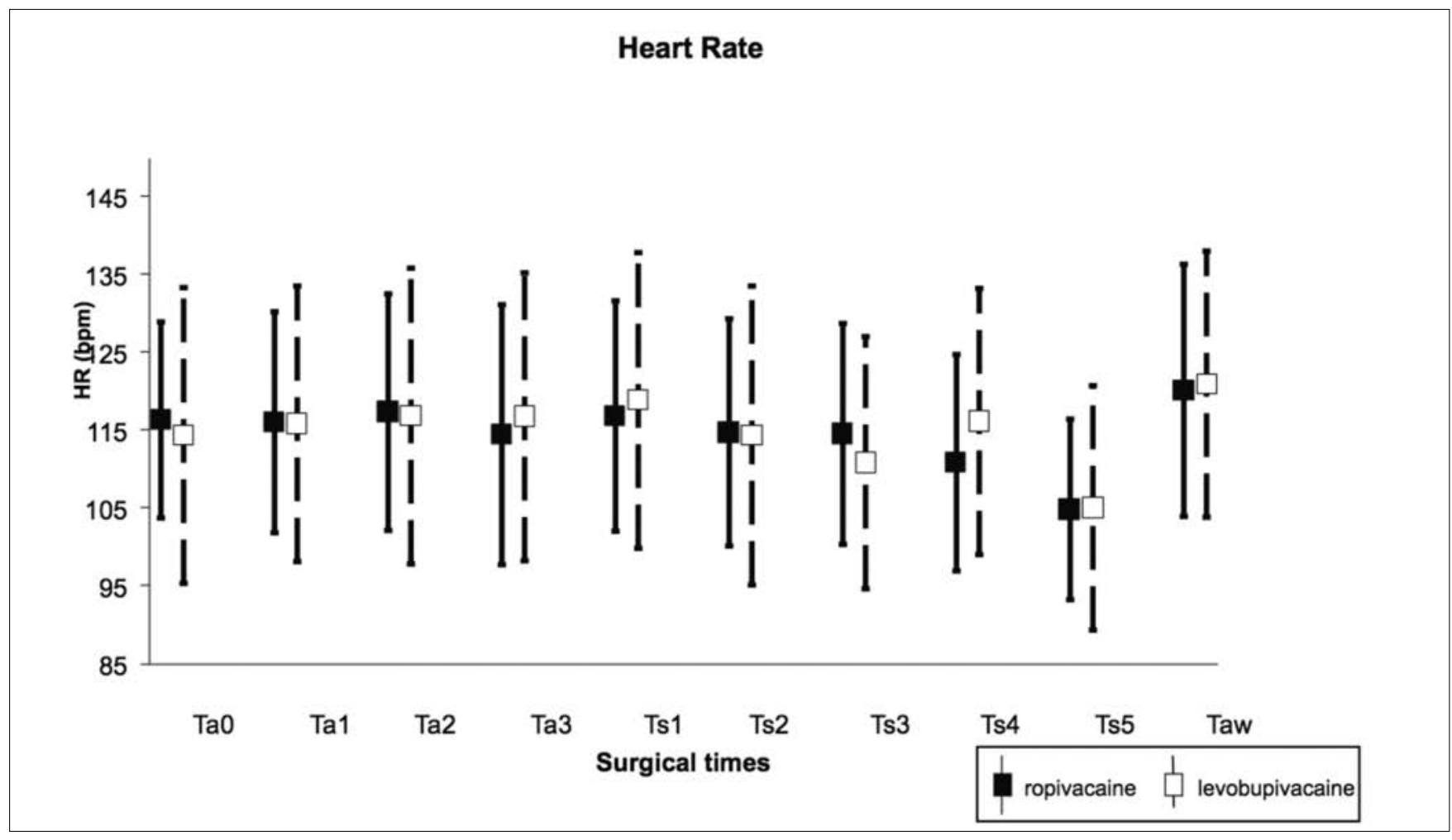

Figure 3.

Trend of heart rate: comparison between levobupivacaine and ropivacaine groups (differences time by time). No significant difference was identified between groups at any time.

the clinical efficacy is an irresolute and ambiguous strategy, whereas the determination of the minimum effective local analgesic concentration (MLAC) is a rational means to overcome such a problem. The MLAC method was applied to 60 women undergoing epidural analgesia with levobupivacaine and bupivacaine and no difference was found $\left(0.083 \%\right.$ versus $0.081 \%$ respectively). ${ }^{28}$ In contrast, using very low concentrations of ropivacaine appears to be $40 \%$ less potent than bupivacaine and almost equipotent with levobupivacaine. ${ }^{29}$

The MLAC of local anaesthetic drugs has never been assessed in children submitted to caudal anaesthesia. However, since the concentration used in pediatric age $(0.20 \%-0.25 \%)$ may reach the upper, flatter portion of the dose-response curve, such a characteristic may lose its importance since in that part of the curve, the potency differences are obscured. Furthermore a recent study showed that there were no significant differences in the $\mathrm{ED}_{50}$ for caudal levobupivacaine and ropivacaine; the potency ratio at $\mathrm{ED}_{50}$ was 0.92 and 0.89 at $\mathrm{ED}_{95}$, indicating that caudal levobupivacaine and ropivacaine have a similar potency. ${ }^{30}$

As for the volume of administration of the local anaesthetic solution, we always used the same volume, in accordance with the literature, ${ }^{16,17,26,30}$ for two reasons. Firstly, all surgery procedures falling within the T12
-T10 methamers appear well covered by an injection of $1 \mathrm{ml} / \mathrm{kg}$ of the local anaesthetic solution, if given through the caudal technique. Secondly, in order to assess cardiocirculatory effects accurately it is necessary to use the same volume $/ \mathrm{kg}$ of local anaesthetic.

Our study shows that the cardiocirculatory parameters corresponded to normal values in the time spans in which they were carried out. This finding indicates the safety of the used drugs, the correctness of the technique and the adequacy of our protocol. In both groups, as expected, a slight increase in heart rate and pressures was observed at the time of incision and at the waking up. The trend of the heart rate was stable without variations between both groups. The blood pressures, above all the diastolic pressures, while remaining within normal ranges, were significantly lower in children who received ropivacaine compared to those who received levobupivacaine.

The study shows a similar heart rate trend in both local anaesthetics. The limited fluctuation in heart rate throughout the whole procedure testifies that the block was efficacious and the interval adopted between the anaesthetic injection and the start of surgery was correct. The dosages and volumes given did not, in fact, produce the negative effects on cardiac innervation (potentially resulting from an extended sympathetic block) that are sometimes observed when both are inappropriate. Simi- 


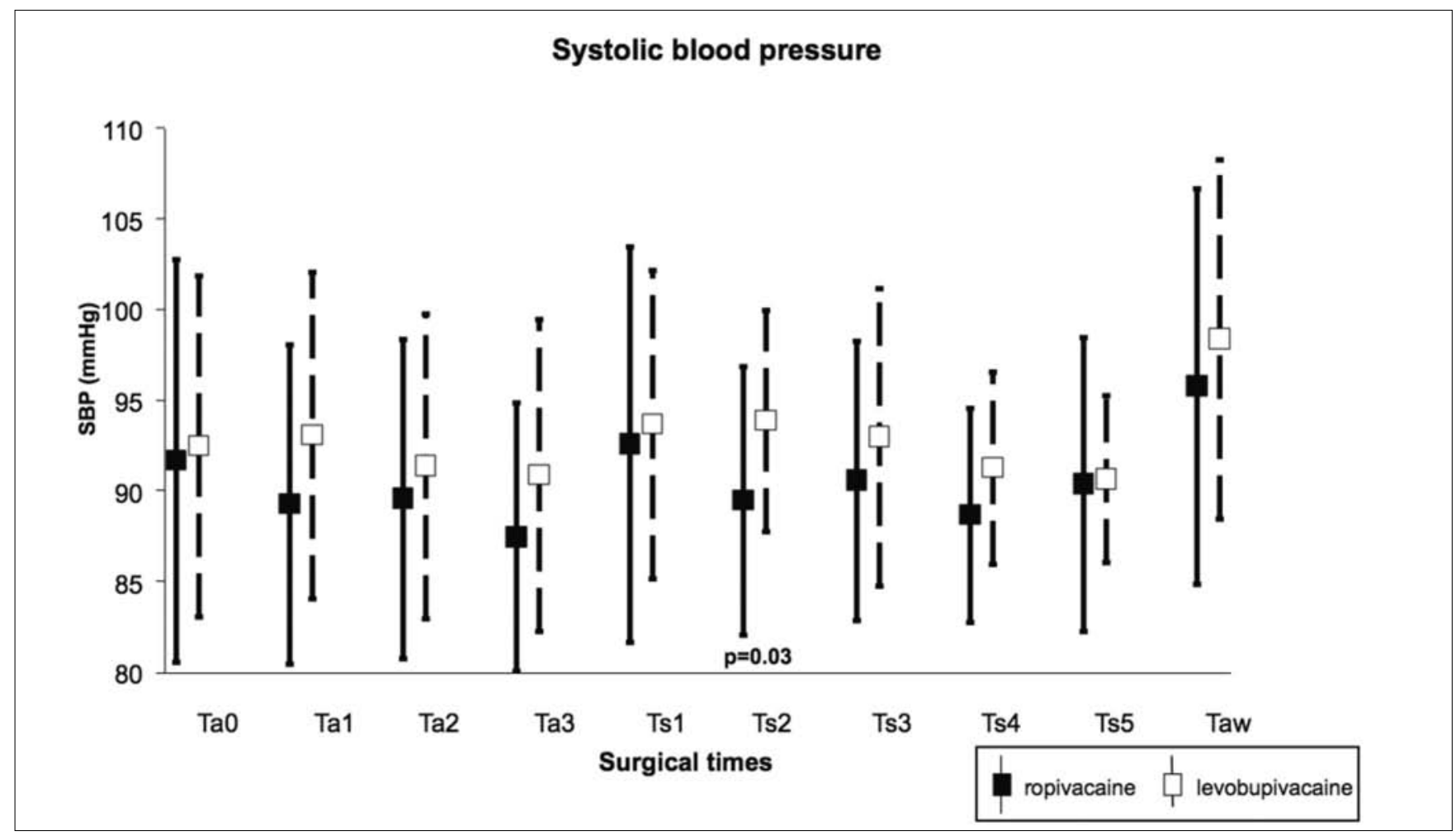

Figure 4

Trend of systolic blood pressure: comparison between levobupivacaine and ropivacaine groups (differences time by time). The levobupivacaine group always shows higher values than the ropivacaine group. A significant difference was seen at TS2.

larly we never witnessed the bradycardia that a fortuitous systematic absorption may induce. Lastly the low variation in heart rate denotes that blood pressure stayed within the physiological ranges, so the increase in heart rate triggered by hypotension as reflex adjustment was never registered. The incidence of sinus bradycardia reported in other studies concerning caudal anaesthesia using bupivacaine in children is mostly related to toxicity episodes resulting from the intravascular absorption or accidental overdose of the local anaesthetic. ${ }^{6,7}$ Such complications are rarely reported when levobupivacaine or ropivacaine are used. One case report cites bradycardia in a pre-term infant after caudal block with ropivacaine and clonidine. ${ }^{31} \mathrm{~A}$ study on 49 children treated with levobupivacaine describes a single episode of bradycardia, but the cause/effect link is extremely uncertain. ${ }^{32}$ More recently, another study in which ropivacaine, bupivacaine and levobupivacaine were given for comparison, mentions an episode of sinus bradycardia in three patients, one in each anaesthetic group. ${ }^{16}$

In our study the arterial pressures too, like the heart rate, show a similar trend at the various time points considered independently from the local anaesthetic used: a low decrease in pressure values began after caudal block, a slight increase at the skin incision, a slight decrease during surgery and an increase at the awakening. Such minor changes, with reference to the anaesthesiologic and surgical times considered, reflect a substantially stable trend throughout the entire procedure. The literature shows that arterial pressure decrease during caudal anaesthesia is the result of vasodilation in the anaesthetized body region. The local anaesthetic induced sympathetic block is likely the cause of this vasodilation. Nevertheless, in contrast to adults, regional anaesthesia in children is characterized by remarkable haemodynamic stability, even when the level of the block reaches the thoracic dermatomes. Particularly during caudal block, limited cardiovascular modifications are observed also with changes in patient position. This seems to be linked to several factors including: 1) the relatively small venous capacity in the lower extremities of children; 2) the relative lack of resting sympathetic peripheral vascular tone; 3) the reduced parasympathetic activity modulating heart rate in children receiving regional block; 4) the fact that in paediatric age the total vascular resistances can be regulated by the reflex mechanism of vasoconstriction of the innervated areas, activated to maintain blood pressure, which balances the effectiveness of the local anaesthetic induced vasodilation sympathetic block. 33,34,35 This last concept has been challenged by a study ${ }^{36}$ which suggests that caudal anaesthesia leads to a blood pooling in the denervated lower extremities (caudal blocked areas) and a 


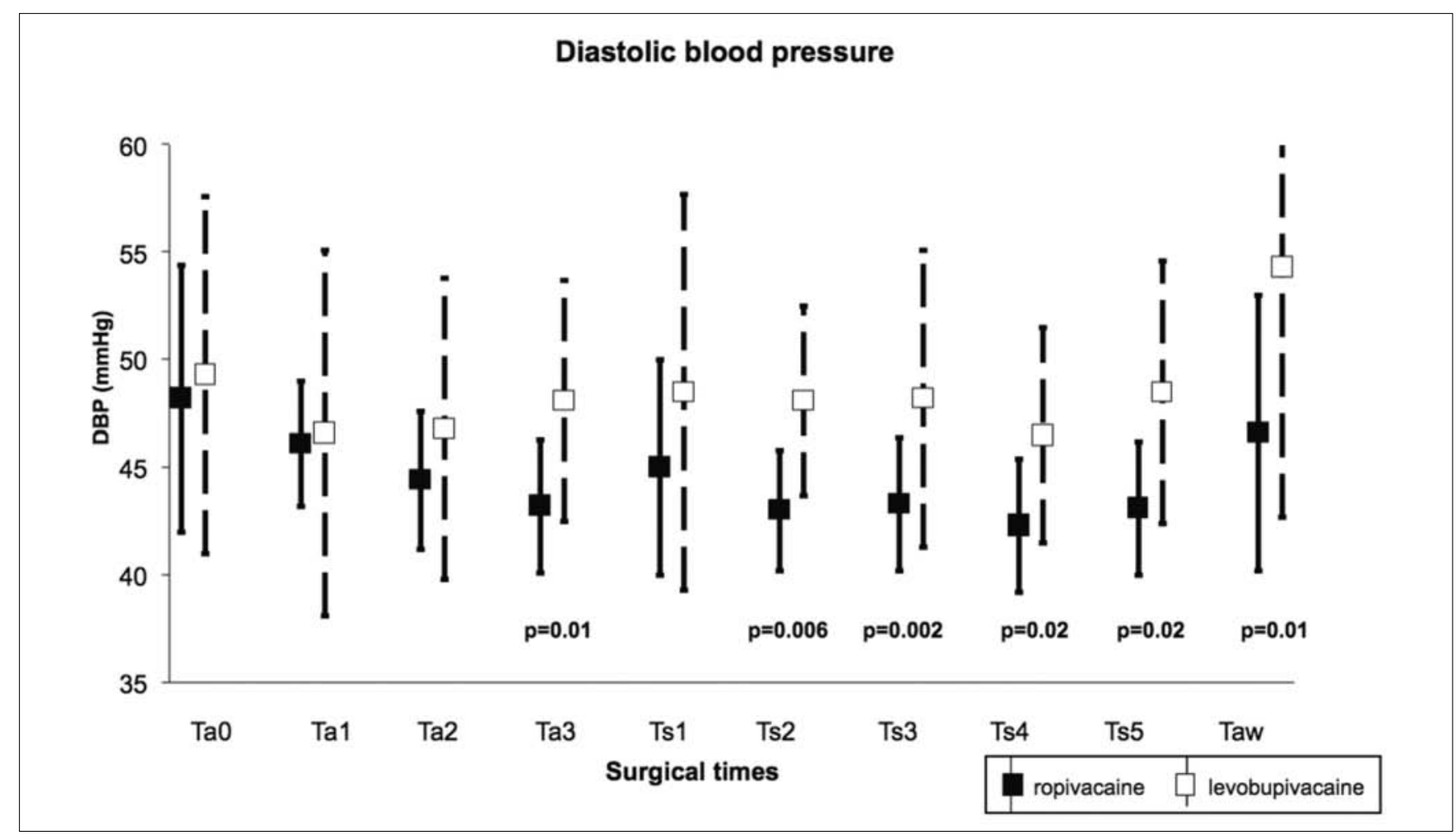

Figure 5.

Trend of diastolic blood pressure: comparison between levobupivacaine and ropivacaine groups (differences time by time). Higher levels were noted in the levobupivacaine group at each time considered. A significant difference was seen at Ta3, TS2, Ts3, Ts4, Ts5 and Taw.

reflex vasoconstriction in the innervated areas. This mechanism has been recently supported by another study. In 48 children who underwent caudal or thoracolumbar epidural anaesthesia through a local anaesthetic mixture combined or not with adrenaline, an increase in cardiac output and a decrease in arterial blood pressure were observed mainly when epinephrine was added to local anaesthetics. The systemic absorption of epinephrine, through the vascular beta-effect, it elicits would probably have limited the reflex mechanism of vasoconstriction. ${ }^{37}$ However, a recent study regarding the haemodynamic effects of levobupivacaine $0.25 \%$ without adrenaline after paediatric caudal anaesthesia, evaluated by transesophageal doppler, showed a decrease in CO (cardiac output), CI (cardiac index), PV (peak velocity), SV (stroke volume) probably resulting from the dilation of the venous vessel and the levobupivacaine onset time; the data do not report the effect on HR or blood pressure. The study unfortunately does not compare the haemodynamic effects of levobupivacaine with those obtained with another local anaesthetic, but rather with those obtained through general anaesthesia associated with remifentanil infusion. The haemodynamic trend observed remained within normal physiological values and in any case tended to return to be restored during the subsequent measurements. ${ }^{18}$
In our study, considering the two groups time by time, the decrease in pressures is statistically higher in patients treated with ropivacaine than levobupivacaine, above all for the diastolic pressure. This finding has never been reported in the paediatric literature, and is difficult to explain. Further studies, also based on echocardiography, that compare the haemodynamic profile of the two local anaesthetics would be useful. In the ensuing discussion we can only advance certain hypotheses.

First of all the general anaesthesia (inhalation/intravenously induction and inhalation maintain) performed in both groups may have influenced the low decrease in arterial pressure, but the technique used was the same for both groups and can not have caused the difference.

Physiopathology demonstrates that among the parameters that can modify the diastolic pressure, total vascular resistance has great importance, while systolic blood pressure is affected by parameters related to cardiac performance, such as contractility. ${ }^{34,38}$ During regional anaesthesia, the contractility can be influenced by a direct action of the drug on the myocardium, sometimes present even at low doses, while the vascular resistances are impaired by the direct pharmacologic effect on the blood vessels or by an indirect effect resulting from a fiber-block sympathectomy. $35,36,37$

A recent experimental study using pressure-volume loops to separate the myocardial from the vascular effects of 
bupivacaine, levobupivacaine and ropivacaine in rabbits shows that levobupivacaine significantly impaired myocardial contractility at doses that could be delivered in normal clinical practice, whereas ropivacaine did not. Levobupivacaine induced a biphasic vascular response, with maximal vasodilatation at a very small dose, thereafter increasing vascular resistance. Ropivacaine induces mild vasoconstriction without compromising cardiac output. The data show that vasoconstriction reflex subsequent both to contractility impairment and to vasodilatation resulting from sympathectomy caudal block is more effective with levobupivacaine. ${ }^{39}$

A first explanation for lower blood pressure values in the ropivacaine group compared to the levobupivacaine group could be a stronger vasoconstriction reflex of the innervated areas during caudal block with levobupivacaine. This fact could explain the presence of higher vascular resistances and, consequently, lower reduction of arterial pressure values in the levobupivacaine group than in the ropivacaine group.

A recent report showed that in women after spinal injection for Caesarean section there is a higher incidence of hypotension using ropivacaine than levobupivacaine. However, the authors supposed that the lowest amount and concentration of levobupivacaine, in association with greater liposolubility may have saved a larger number of beta-fibres leading to a lower sympathetic block..$^{40}$ This justification is not applicable to our study considering that the concentration of levobupivacaine is greater than that of ropivacaine. However this study could give rise to a second hypothesis: the different blood pressure values in our two groups may be caused by the different chemical characteristics of the molecules of the two drugs, determining two different phamacokinetics. ${ }^{12}$ To exemplify, levobupivacaine is more liposoluble than ropivacaine. This difference together with the vascularity and fat content of the epidural space in paediatric age and the low anaesthetic solution concentration of the drugs used could produce a lesser block of the C-sympathetic nervous fibers in the levobupivacaine group resulting in a lower fall in the blood pressure values compared to the ropivacaine group. Since the studies concerning the pharmacokinetic and pharmacodynamic profile of levobupivacaine give little space to this aspect, ${ }^{18,41,42}$ further comparative investigations need to be performed in children after levobupivacaine and ropivacaine administration.

\section{Conclusions}

Paediatric caudal anaesthesia is an effective method with an very infrequent complication rate. The data of our study led us to formulate cardiovascular hypotheses that, even though supported by some papers, need further investigation. This study confirms the effectiveness and the safety of both agents, ropivacaine and levobupivacaine, when used for caudal anaesthesia. Although these two compounds are similar, they are different enough to present different cardiovascular performance profiles. The different cardiocirculatory findings of the two local anaesthetics should, in fact, be reconsidered before regional anaesthesia in children with high haemodynamic risk.

\section{Acknowledgements}

We are very grateful to Irene Domenichini for her assistance in the statistical analysis of the manuscript.

\section{References}

1 Gunter JB. Benefit and risks of local anaesthetics in infants and children. Paediatr Drugs 2002;4:649-672.

2 Tuncer S, Yosunkaya A, Reisli $\mathrm{R}$ et al. Effect of caudal block on stress responses in children. Pediatr Int 2004;46(1):53-57.

3 Giaufre E, Dalens B, Gombert A. Epidemiology and morbidity of regional anestesia in children. A one-year prospective survey of the French-language Society of Pediatric Anesthesiologists. Anesth Analg 1996;83:904-912.

4 Marhofer P, Koinig H, Kapral S. The choice of drugs for caudal anaesthesia in children. An overview. Anaesthesist 2003;52(1):55-67.

5 Dalens B, Hasnaoui A. Caudal anesthesia in pediatric surgery: success rate and adverse effects in 750 consecutive patients. Anesth Analg 1989;68:83-89.

6 Uejima T, Suresh S. Is $0.375 \%$ bupivacaine safe in caudal anesthesia in neonates and young infants? Anesth Analg 2002;94(4):1041.

7 Mevorach DL, Perkins FM, Isaacson SA. Bupivacaine toxicity secondary to continuous caudal epidural infusion in children. Anesth Analg 1993;77(6):1305-1306.

8 McCloskey JJ, Haun SE, Deshpande JK. Bupivacaine toxicity secondary to continuous caudal epidural infusion in children. Anesth Analg 1992;75(2):287-290.

9 Wang RD, Dangler LA, Greengrass RA. Update on ropivacaine. Expert Opin Pharmacother 2001;2(12):2051-2063.

10 McClellan KJ, Faulds D. Ropivacaine: an update of its use in regional anaesthesia. Drugs 2000;60(5):1065-1093.

11 Mazoit JX, Dalens B. Ropivacaine in infants and children. Curr Opin Anaesthesiol 2003; 16(3):305-307.

12 Foster RH, Markham A. Levobupivacaine: a review of its pharmacology and use as a local anaesthetic. Drugs 2000;59(3):551-579.

13 McClellan KJ, Spencer CM. Levobupivacaine. Drugs 1998;56(3):355-62.

14 Mazoit JX, Decaux A, Bouaziz H, Edouard A. Comparative ventricular electrophysiologic effect of racemic bupivacaine, levobupivacaine, ropivacaine on the isolated rabbit heart. Anesthesiology 2000;93:784-792.

15 Morrison SG, Dominguez JJ, Frascarolo P, Reiz S. A comparison of the electrocardiographic cardiotoxic effects of racemic bupivacaine, levobupivacaine, and ropivacaine in anesthetized swine. Anesth Analg 2000;90:1308-1314. 
16 Ingelmo PM, Locatelli BG, Sonzogni W et al. Caudal 0.2\% ropivacaine is less effective during surgery than $0.2 \%$ levobupivacaine and $0.2 \%$ bupivacaine: a double-blind, randomized, controlled trial. Paediatr Anaesth 2006;16(9):955-961.

17 Ivani G, De Negri P, Lonnqvist PA et al: Caudal anesthesia for minor pediatric surgery: a prospective randomized comparison of ropivacaine $0.2 \%$ vs levobupivacaine 0.2\%. Paediatr Anaesth 2005;15(6):491-494.

18 Galante D, Pellico G, Meola S et al: Hemodynamic effects of levobupivacaine after pediatric caudal anesthesia evaluated by transesophageal doppler. Pediatr Anesth 2008;18:1066-1074.

19 Gregory GA. Monitoring during surgery. In: Gregory GA editor. Pediatric Anesthesia. 4th ed. New York: Churchill Livingstone; 2002. p. 249-265.

20 Tobias JD. Controlled hypotension in children: a critical review of available agents. Paediatr Drugs 2002;4(7):439-453.

21 Ivani G, De Negri P, Conio A et al. Comparison of epidural bupivacaine, ropivacaine and levobupivacaine for pediatric caudal anesthesia: effects on postoperative analgesia and motor block. Reg Anesth Pain Med 2002;27:157161.

22 De Negri P, Ivani G, Tirri T et al. Comparison of epidural bupivacaine, levobupivacaine and ropivacaine on postoperative analgesia and motor block. Anesth Analg 2004;99(1):45-48.

23 Breschan C, Jost R, Krumpholz R et al. A prospective study comparing the analgesic efficacy of levobupivacaine, ropivacaine and bupivacaine in pediatric patients undergoing caudal blockade. Paediatr Anaesth 2005;15(4):301-306.

24 Astuto M, Disma N, Arena C. Levobupivacaine 0.25\% compared with ropivacaine $0.25 \%$ by the caudal route in children. Eur J Anaesthesiol 2003;20(10):826-830.

25 Locatelli B, Ingelmo P, Sonzogni W et al. Randomized, double-blind, phase III, controlled trial comparing levobupivacaine $0.25 \%$, ropivacaine $0.25 \%$ and bupivacaine $0.25 \%$ by the caudal route in children. $\mathrm{Br} \mathrm{J}$ Anaesth 2005;94(3):366-371.

26 Frawley GP, Downie S, Huang GH. Levobupivacaine caudal anesthesia in children: a randomized double-blind comparison with bupivacaine. Paediatr Anaesth 2006;16(7):754-760.

27 Ivani G, De Negri P, Lonnqvist PA et al. A comparison of three different concentrations of levobupivacaine for caudal block in children. Anesth Analg 2003;97(2):368-371.

28 Lyons G, Columb MO, Wilson RC et al. Epidural pain relief in labour: potencies of levobupivacaine and racemic bupivacaine. $\mathrm{Br} \mathrm{J}$ Anaesth 1998;81:899-901.
29 Polley LS, Culumb MO, Naughton NN. Relative analgesic potencies of ropivacaine and bupivacaine for epidural analgesia in labor: implications for therapeutic indexes. Anesthesiology 1999;90:944-950.

30 Ingelmo $\mathrm{P}$, Frawley $\mathrm{G}$, Astuto $\mathrm{M}$ et al. Relative analgesic potencies of levobupivacaine and ropivacaine for caudal anesthesia in children. Anesth Analg 2009;108(3):805-813.

31 Galante D. Preoperative apnea in a preterm infant after caudal block with ropivacaine and clonidine. Paediatr Anaesth 2005;15(8):708-709.

32 Taylor R, Eyres R, Chalkiadis GA, Austin S. Efficacy and safety of caudal injection of levobupivacaine, $0.25 \%$, in children under 2 years of age undergoing inguinal hernia repair, circumcision or orchidopexy. Paediatr Anaesth 2003;13:114-121.

33 Buchhorn R, Hulpke-Wette M, Nothroff J, Paul T. Heart rate variability in infants with heart failure due to congenital heart disease: reversal of depressed heart rate variability by propranolol. Med Sci Monit 2002;8(10):661-666.

34 Strafford MA. Cardiovascular physiology. In: Motoyama EK, Davis PJ editors. Smith's: Anesthesia for infants and children. 6th ed. St Louis: C. V. Mosby; 1996. p. 69-104.

35 Larousse E, Asehnoune K, Dartayet B et al. The hemodynamic effects of pediatric caudal anesthesia assessed by esophageal doppler. Anesth Analg 2002;94:1165-1168.

36 Payen D, Ecoffey C, Carli P, Dubousset AM. Pulsed Doppler ascending aortic, carotid, brachial and femoral artery blood flows during caudal anesthesia in infants. Anesthesiology 1987;67:681-685.

37 Raux O, Rochette A, Morau E, Dadure C, Vergnes C, Capdevila X. The effects of spread of block and adrenaline on cardiac output after epidural anesthesia in young children: a randomized, double-blind, prospective study. Anesth Analg 2004;98:948-955.

38 Kern FH, Bengur AR, Bello EA. Developmental cardiac physiology. In: Rogers MC editor. Texbook of pediatric intensive care. 3th ed. Baltimore: Williams \& Wilkins; 1996. p. 397-418.

39 Royse CF, Royse AG. The myocardial and vascular effects of bupivacaine, levobupivacaine, and ropivacaine using pressure volume loops. Anesth Analg 2005;101:679-687.

40 Parpaglioni R, Frigo MG, Lemma A, Sebastiani M, Barbati G, Celleno D: Minimum local anaesthetic dose (MLAD) of intrathecal levobupivacaine and ropivacaine for Caesarean section. Anaesthesia 2006;61(2):110-115.

41 Chalkiadis GA, Eyres RL, Cranswick, Taylor RH, Austin S: Pharmacokinetics of levobupivacaine $0.25 \%$ following caudal administration in children under 2 years of age. Br J Anaesth 2004;92(2):218-222.

42 Cortínez LI, Fuentes R, Solari S, Ostermann P, Vega M, Muñoz HR: Pharmacokinetics of levobupivacaine $(2.5 \mathrm{mg} / \mathrm{kg})$ after caudal administration in children younger than 3 years. Anesth Analg 2008;107(4):1182-1184. 